\title{
Correction to: An automatic approach for cell detection and segmentation of corneal endothelium in specular microscope
}

\author{
Ranit Karmakar $^{1}\left[\right.$ [ Saeid Nooshabadi ${ }^{1} \cdot$ Allen Eghrari $^{2}$
}

Published online: 29 November 2021

๑) Springer-Verlag GmbH Germany, part of Springer Nature 2021

\section{Correction to: Graefe's Archive for Clinical and Experimental Ophthalmology https://doi.org/10.1007/s00417-021-05483-8}

The original version of this article unfortunately contained a mistake. The IRB number under the Ethics approval was missing. The corrected text is given below.

Ethics approval The data used in this research was collected under IRB number IRB00039261 at the Johns Hopkins University. All the data was deidentified before sharing with the researchers at the Michigan Technological University; hence, they received a waiver for the analysis work.

This is being corrected in this publication.

Publisher's note Springer Nature remains neutral with regard to jurisdictional claims in published maps and institutional affiliations.

The original article can be found online at https://doi.org/10.1007/ s00417-021-05483-8.

Ranit Karmakar

rkarmaka@mtu.edu

1 Department of Electrical and Computer Engineering, Michigan Technical University, Houghton, MI, USA

2 Department of Ophthalmology, School of Medicine, Johns Hopkins University, Baltimore, MD, USA 